\title{
Muralf
}

INTERNACIONAL

\section{O Programa Nuclear Iraniano e o Acordo E3/EU+3 The Iranian Nuclear Program and the E3/EU+3 Agreement ${ }^{1}$}

\section{ELIAS DAVID MORALES MARTINEZ ${ }^{2}$ GIOVANI BENITO MENA DEL PRETE ${ }^{3}$}

Resumo: O artigo analisa o desenvolvimento do programa nuclear iraniano e a sua relação com o acordo entre o Irã e o grupo E3/EU+3. A partir de uma análise histórica, consideramos os diferentes momentos do programa nuclear iraniano desde a sua criação, que contou com o apoio estadunidense nos anos 1950, passando pela sua paralisação com a Revolução Islâmica de 1979. A partir dos anos 1990 evidenciamos três fases do programa nuclear.

A primeira com o presidente Kathami, responsável pela sua retomada. Já no século XXI o presidente Ahmadinejad imprime ao programa nuclear o discurso dissuasório utilizando-o como ferramenta política, a qual foi acertadamente aproveitada pelo presidente Rohani, quem iniciou as negociações com o grupo E3/EU+3 para o acordo histórico sobre o programa nuclear do Irã (2013-2015).

Palavras-chave: Irã, Programa Nuclear Iraniano, Grupo E3/EU+3.

Abstract: The article analyzes the development of the Iranian nuclear program and its relation to the agreement between Iran and the E3/EU+3 group. From an historical analysis, we consider the different milestones of the Iranian nuclear program from the time when its inception, which was supported by the U.S. since the 1950s, until its closure from the Islamic Revolution in 1979. We noted three phases of this program starting from the 1990's. The first phase occurred during the time of President Khatami, who was responsible for the resumption (of the program). At the beginning of the XXI century President Ahmadinejad marked the roadmap of the nuclear program with a dissuasive speech using it as a political tool, which was rightly seized by President Rohani, who initiated the negotiations with the E3/EU+3 group for the historic agreement for Iran's nuclear program (2013-2015).

Keywords: Iran; Iranian Nuclear Program, E3/EU+3 Group.

\footnotetext{
${ }^{1}$ Esta pesquisa contou com apoio financeiro do CNPq/CAPES.

${ }^{2}$ Doutor em Integração da América Latina pela Universidade de São Paulo (USP). Professor da Pós-Graduação em Ciências Humanas e Sociais e Professor do Bacharelado em Relações da Universidade Federal do ABC (UFABC). Endereço para correspondência: Rua Arcturus, 03 - Bloco Delta, Sala 317, Bairro Jardim Antares, São Bernardo do Campo, SP. CEP 09606070. Email: david.morales@ufabc.edu.br

${ }^{3}$ Bacharel em Ciências e Humanidades (UFABC) e graduando em Relações Internacionais (UFABC). Email: giovani.delprete@gmail.com
} 


\section{Introdução}

O século XX, também conhecido como o "Século das Guerras", foi o período histórico no qual se estabeleceram as nuances internacionais que vieram influenciar os desdobramentos do cenário politico internacional no início do século XXI. Interessante observar que, na visão de Hobsbawn (1995), o século XX nasce com a deflagração da Primeira Guerra Mundial em 1914, levando posteriormente a um novo confronto mundial em 1939. Logo após finalizada esta Segunda Guerra Mundial, em 1945 se dá inicio à Guerra Fria que perdurou durante 46 anos, terminando com a queda do Muro de Berlim em 1989 e, em 1991, com a desintegração de uma das superpotências, a ex-União das Repúblicas Socialistas Soviéticas (URSS). Assim, o curto século XX se encerra deixando as bases que modificariam, significativamente, o contexto internacional e as lógicas que se estabeleceriam no novo cenário político mundial para o século XXI.

Os primeiros anos do século XXI são percebidos como um período de crescente escalada de contendas, as quais tem abalado o mundo. Neste século há uma grande preocupação dos policymakers das potências hegemônicas ocidentais com relação à emergência do terrorismo como uma ameaça global que deve ser combatida e perseguida, sobretudo após os atentados de 11 de setembro de 2001 em Nova Iorque. Estes ataques desencadearam uma série de ações e determinações dos diferentes governos enquadrados na política internacional da Guerra ao Terror liderada pelos Estados Unidos, e que, através de políticas ostensivas e estratégias militares têm aprofundado problemas decorrentes da Guerra Fria, principalmente no tratamento com a delicada relação com os países do Oriente Médio.

É neste cenário que foi desenvolvida a "Doutrina Bush", a qual repercute até hoje em debates teóricos, devido às suas consequências ainda em vigor. A política externa implantada pelo então presidente dos Estados Unidos, George W. Bush após o atentado ao World Trade Center voltou-se em direção ao que chamou de "Eixo do Mal" (Irã, Iraque e Coreia do Norte). Estes países foram acusados pelos Estados Unidos e seus aliados de financiarem ações e de protegerem grupos terroristas assentados nos seus territórios, capazes de gerenciar uma ampla rede espalhada pelo mundo, ameaçando assim a paz e a segurança internacionais. 


\section{Muralf}

INTERNACIONAL

No governo Obama há, notadamente, uma mudança da práxis da política externa dos Estados Unidos em relação ao chamado "Eixo do Mal". Isto foi interpretado como uma paulatina diminuição das tensões tradicionais, corriqueiras e diretas entre o Ocidente e o Oriente Médio. A questão Síria sobre a guerra civil entre as forças a favor e contra o regime de Bashar al Assad e o acordo sobre o programa nuclear iraniano iniciado em 2013 são dois momentos que exemplificam este parco e inicial esfriamento dos ânimos nessas regiões.

Especificamente, em relação a reaproximação dos Estados Unidos com a atual composição de governo do Irã para discutir o programa nuclear persa, destaca-se o fato de terem acontecido mudanças significativas na percepção mútua destes dois países que, desde novembro de 2013, têm conseguido estabelecer uma mesa de negociações sem precedentes na história. Esta reaproximação gerou um acordo inicial de manter, por um período de tempo renovável, as negociações do desenvolvimento do programa nuclear iraniano com a participação por um lado, dos Estados Unidos, Rússia e China, como membros não-europeus do Conselho de Segurança da ONU, e por outro lado, França, Reino Unido,
Mural Internacional

V. $6 \mid$ N. 2

JUL-DEZ 2015 enquanto parte europeia do Conselho, mais a Alemanha.

O grupo conformado ficou conhecido como E3/EU+3. Assim sendo, esta nova coalizão de geometria variável ficou voltada para o debate e tomada de decisão com relação ao intuito do Irã em desenvolver tecnologia nuclear aprimorada. O novo grupo constitui o objeto de estudo deste artigo, sendo o objetivo, a análise da articulação do programa nuclear iraniano como uma ferramenta de dissuasão para ser barganhada por um apaziguamento das relações entre o país e as potências ocidentais, as quais, por muito tempo, relutaram em reconhecer a concretização de um Irã "nuclearizado", mas que a partir de 2013, vem aliviando as pressões que sufocaram os diálogos para a paz não somente no Irã, como também na região do Oriente Médio.

O presente texto está estruturado em três partes. A primeira consiste numa análise sobre a gênese do programa nuclear iraniano na década de 1950 e as implicações políticas que acompanham o seu desenvolvimento; a segunda contempla o acordo negociado entre o Irã e o grupo E3/EU+3, durante o período de 2013-2015, para que sejam entendidos quais os termos pactuados e quais as condicionalidades derivadas 
das negociações; e, por fim, na terceira são feitas algumas considerações finais que interpretam o programa nuclear iraniano em diferentes fases e expõem a importância de um acordo como este para o Irã.

\section{O programa nuclear iraniano}

Embora conste atualmente nos principais debates internacionais, o programa nuclear iraniano não é um assunto recente. Em 1950 o Irã iniciou suas pesquisas no setor nuclear partilhando do auxílio estadunidense. Tratava-se da política estadunidense denominada de "Átomos para a Paz", que visava desenvolver a tecnologia nuclear voltada exclusivamente para fins pacíficos. O Presidente dos Estados Unidos, Dwight Eisenhower, discursando na Assembleia da ONU em 1953, não só propôs o programa de uso pacífico da tecnologia nuclear, como também a criação do que se tornaria a Agência Internacional de Energia Atômica - AIEA (Bruno, 2010). Essa estratégia benevolente nada mais era que uma jogada política para tentar desestabilizar o principal inimigo estadunidense no recente período denominado Guerra Fria: a União Soviética. Ao assumir o papel de "defensor da paz" os Estados Unidos acumulariam pontos positivos com a opinião pública doméstica e internacional.

Assim sendo, em 1957, o ministro iraniano Xa Reza Pahlevi assinou com os EUA um acordo de cooperação nuclear civil e dois anos depois foi negociado o fornecimento de um reator com capacidade para cinco megawatts e, na década de 1970, foram assinados contratos com a França e Alemanha com o intuito de construir mais de vinte reatores (Ibañez 2011, p. 136).

Pelo fato do Irã ter assinado em 1968 e ratificado em 1970 o Tratado de Não Proliferação Nuclear (TNP), as potências ocidentais logo perceberam o significado estratégico que representaria manter o Irã como aliado e funcionando como "país tampão" diante da influência soviética que pretendia se espalhar em direção ao Oriente Médio. Por tal motivo, em 1976, o presidente dos Estados Unidos, Gerald Ford, assina um novo acordo se comprometendo em fornecer instalações para a montagem de um complexo industrial de natureza nuclear com o objetivo de garantir a segurança energética que o país demandava para enfrentar os desafios das últimas décadas do século XX (Garcia 2012, p.3).

Em 1979, a Revolução Islâmica marcou uma brusca inflexão nas relações entre 


\section{Muralf}

INTERNACIONAL

Teerã e o mundo ocidental, marcando um completo distanciamento da política dos Estados Unidos e a paralização dos acordos de cooperação energética e nuclear que estavam em vigência. $\mathrm{O}$ aiatolá Ruhollah Khomeini assumiu a liderança política e religiosa declarando o país uma República Islâmica. Neste novo recorte sócio-político, Khomeini entendia que a energia atômica e os projetos que estavam se desenvolvendo em fase inicial não condescendiam com os novos valores da recém fundada República (Ibañez 2011, p.136). Assim, os contratos foram cancelados e o programa nuclear ficou estagnado durante vários anos. $\mathrm{O}$ que mais incomodou o novo governo do Irã foi o fato de que tanto a Alemanha quanto a França não devolveram o dinheiro recebido para a construção dos reatores em Busher e Darkhouin respectivamente (Garcia 2012, p. 3).

Durante a guerra com o Iraque (19801988) vários reatores de capacidade modesta foram destruídos pelas forças iraquianas. Igualmente, o exército iraquiano utilizou armas de destruição em massa contra a população iraniana, principalmente armas químicas, o que significou para o Irã uma sensação de extrema vulnerabilidade e de frágil segurança em nível regional. Esses fatores pressionaram a República Islâmica aceitar o cessar-fogo e pensar
Mural Internacional

V. $6 \mid$ N. 2

JUL-DEZ 2015 estrategicamente um novo contexto no qual pudessem dar seguimento, mesmo que secretamente, ao programa nuclear que tinha sido abandonado.

A conjuntura do pós guerra com o Iraque estabeleceu um panorama bastante dinâmico nas pretensões iranianas de retomar a política nuclear com vistas a consolidar o país com esta tecnologia. Progressivamente, esta política passou a ser percebida como fundamental e estratégica. Destacam-se a participação da Rússia e do Paquistão através do fornecimento de conhecimentos e segredos dos respectivos programas nucleares $\mathrm{e}$ também da Argentina pelas pretensões iniciais de comercializar reatores com o Irã. Na visão de Ibañez:

Acabada la guerra con Irak en 1988, Irán reinicia con el Presidente Rafsanjani su programa atómico, para lo cual Rusia, China y Argentina fueron los principales proveedores de tecnología. Argentina, ante la insistencia estadounidense, canceló la venta de un reactor experimental a Irán en 1992. Nuevas presiones favorecieron la disminución de la asistencia china en 1998. El mantenimiento de la cooperación rusa permitió a Irán proseguir con la construcción de la planta nuclear de Bushehr, al sur del país, una instalación que inició su desarrollo gracias al apoyo estadounidense y alemán en los años setenta (Idem 2011, p. 136). 
Neste sentido, o Irã intentou, com ajuda da Espanha e da Alemanha, reconstruir os reatores de Busher, que foram destruídos durante a guerra contra o Iraque, mas não houve um compromisso firme por parte desses países. Assim, a China, durante os anos 1990, estabeleceu acordos de transferência tecnológica para a construção da usina de Arak, sendo capaz de enriquecer urânio mediante tecnologia laser (Garcia 2012, pp. 3-4). Igualmente, a aproximação do governo iraniano com o Paquistão durante década de 1990, especialmente os contatos estabelecidos com Abdul Khan "pai da bomba atômica paquistanesa", e os testes nucleares paquistaneses bem sucedidos em 1998, aprofundaram ainda mais as suspeitas que os países ocidentais tinham em relação à retomada do programa nuclear iraniano, principalmente no relacionado com o perfil belicoso.

Os atentados de 11 de setembro de 2001 demarcaram uma mudança na percepção dos Estados Unidos sobre o desenvolvimento de tecnologia nuclear por parte do Irã. A partir de então, os estadunidenses passaram a enxergar como ameaça aos interesses nacionais a capacidade nuclear do Irã e o país se transformou em alvo direto da agenda de segurança internacional colocada pelo governo Bush, incluindo o país no chamado "Eixo do Mal".

Em 2002, os temores do Ocidente aprofundaram-se quando o grupo opositor ao regime iraniano, o Comitê Nacional de Resistência, apresentou provas da existência de certas usinas nucleares no país que ainda não tinham sido declaradas nas inspeções feitas pela Agência Internacional de Energia Atômica - AIEA. Conforme explica ElBaradei:

Como se não bastassem duas situações de verificação nuclear em meados de 2002, a AIEA começou a receber informações sobre um terceiro caso. Imagens de satélite de Natanz, pequena cidade da província de Isfahan, região central do Irã, mostravam a construção de uma grande instalação nuclear com detalhes perceptíveis, sugerindo que podia se tratar de uma usina de enriquecimento de urânio. Por volta de agosto, o Conselho Nacional de Resistência do Irã reuniu uma coletiva de imprensa em Washington, na qual afirmou que o país estava construindo uma usina nuclear secreta em Natanz (ElBaradei 2011, p. 133).

Durante todo o governo do Mohammad Khatami (1997-2005) a ciência e a tecnologia nucleares com fins pacíficos se tornaram centrais nos objetivos nacionais do país e foram elevados ao 


\section{Muralf}

INTERNACIONAL
Mural Internacional

V. $6 \mid$ N. 2

JUL-DEZ 2015 nível de interesse máximo e de segurança nacional. Isto, contrastou significativamente com as dificuldades que a AIEA encontrou para determinar o grau de potencialidade de enriquecimento de urânio nas usinas recém descobertas. Tais dificuldades se resumiram nas barreiras que o governo iraniano colocou à entrada dos inspetores, defendendo o seu direito de manter, como segredo de Estado, o desenvolvimento de sua tecnologia nuclear. Igualmente, a desconfiança do Irã em relação ao Ocidente, uma vez deflagrada a Guerra do Iraque em 2003, levou o país se radicalizar ainda mais, sofrendo as retaliações derivadas das sucessivas pressões diplomáticas e penalidades de naturezas diversas aprovadas nas distintas resoluções do Conselho de Segurança das Nações Unidas (Ibañez 2011, p. 137).

Em 2005, o ultra-conservador, fundamentalista islâmico e ex-prefeito de Teerã, Mahmoud Ahmadinejad, chegou ao poder em eleições marcadas por denúncias de fraude, porém contou com o reconhecimento oficial da maioria dos países da região, mesmo com ressalvas e profundas desconfianças pelas potências ocidentais. Com Ahmadinejad já era de se esperar a virada que o novo governo teria com relação à inserção do país no contexto internacional e o plano nuclear que se reconfiguraria durante sua administração. Segundo Vizentini:
Ahmadinejad, um professor universitário frugal, prometendo a defesa dos princípios fundadores da Revolução, o combate aos grupos de interesse que se apoiam na cúpula religiosa, a corrupção, a defesa dos pobres contra os novos ricos e as 'mil famílias capitalistas remanescentes', mas principalmente, transformar o Irã numa potência respeitada internacionalmente.
Os programas sociais, o projeto nuclear e suas bravatas diplomáticas permitiram-lhe um apoio popular amplo, que foi respaldado pela elite religiosa, que se encontra em processo de desgaste (Idem, 2010, p. 2).

Independentemente da orientação política e religiosa, houve no Irã um fator particularmente evidenciado no final do século XX: o intuito de tornar a política nuclear como política de Estado e elevar o nível do país no contexto internacional. Nesse sentido, Zaccara (2006) argumenta que o desenvolvimento do programa nuclear se tornou uma questão de prestígio nacional para o Irã, que vinha sendo declarado abertamente desde antes das eleições de 2005:

Unos meses antes de las elecciones presidenciales de junio de 2005, y ante cierta parálisis en 
las negociaciones, el propio Katami hizo firmes declaraciones respecto a la soberanía iraní sobre su programa nuclear y la decisión de la clase política nacional de continuar con el proceso de enriquecimiento de uranio. Esta declaración no fue otra cosa que la demostración del consenso existente en cuanto a la legitimidad interna del deseo de convertir Irán en potencia nuclear, más allá de que signifique la posibilidad de que esa energía sea susceptible de convertir-se en armamento nuclear. Las declaraciones de Ahmadinejad cuando asumió su cargo, y la rotura de los precintos del OIEA, junto con la decisión de reiniciar el proceso de enriquecimiento de uranio por parte de su gobierno, han hecho saltar la alarma en cuanto a la posibilidad de que el actual Irán esté más decidido que nunca a conseguir el arma nuclear (Zaccara 2006, pp. 110-120).

O desgaste da cúpula religiosa e a crescente massa jovem pós-guerras e pós-revolução suscitaram novos interesses nacionais, muitos destes flertando com um pujante Ocidente globalizante. Dentre os novos elementos de barganha está o polêmico programa nuclear, fundamental para aumentar o grau de influência na região.

Os países do Ocidente, liderados pelos Estados Unidos, têm observado o assunto com bastante atenção, visto que um Estado que foi enquadrado no "Eixo do Mal", tido como um rogue state, isto é, contra os ideais ocidentais, especialmente estadunidenses, e cuja conduta é identificada como fora do padrão aceitável por normas internacionais, poderia desenvolver uma bomba atômica, incluindo-se no seleto grupo de países que ameaçam a paz no mundo.

Conforme argumentam Cirincione, Wolfsthal e Rajkumar (2005) o Irã possui nove instalações nucleares entre centros de pesquisa e usinas de energia. Bonab, Arak, Teerã, Natanz, Adakan, Fordow/Qom e Parchin fazem parte deste quadro. Busher, a principal, foi um projeto abandonado no pósRevolução de 1979 e retomado em 1995 com o apoio russo. A usina começou a entregar eletricidade em setembro de 2011, tornando-se a primeira usina nuclear civil do Oriente Médio, tendo uma posição estratégica próxima ao Golfo Pérsico. Das minas para a extração de urânio, o Irã conta com três: Gachin, Saghand e Yazd.

De igual forma, o enriquecimento do urânio no país tem gerado desconfiança entre os Estados vizinhos (Arábia Saudita e Israel) e os mais distantes (Estados Unidos e os integrantes da União Europeia), visto que, uma vez dominada a tecnologia nuclear, uma bomba facilmente poderia ser construída. O Irã defende que deseja 


\section{Muralf}

INTERNACIONAL

enriquecer urânio para fins pacíficos, como no campo da medicina, por exemplo. Para isto torna-se necessário ao país submeter-se a acordos e órgãos de fiscalização internacionais, demonstrando ao mundo que não está vinculado à projetos nucleares que sejam belicosos.

Nesse sentido, podem ser identificados dois momentos políticos recentes da história do país que operaram a política nuclear iraniana de duas formas distintas, mas com um único objetivo. $\mathrm{O}$ primeiro é caracterizado pela ascensão do líder fundamentalista Mahmoud Ahmadinejad à presidência do país em 2005, sendo reeleito em 2009, governando até 2013. Talvez o seu papel mais destacado é o do resgate ao nacionalismo, carente para a população do Irã. É nitidamente Ahmadinejad quem ressuscita parte do apelo aos ideais que a Revolução de 1979 havia evidenciado. Seu posicionamento no cenário internacional em relação ao programa nuclear desagradou as hegemonias nucleares e causou um desgaste ainda maior com o governo norte-americano e com o Conselho de Segurança da ONU.

Como resultado dos sucessivos embates, o Irã foi submetido a mais embargos econômicos e disputas diplomáticas nos diferentes foros internacionais. $\mathrm{O}$
Mural Internacional

V. $6 \mid$ N. 2

JUL-DEZ 2015 resultado pode ser avaliado em duas dimensões. Por um lado ficou demonstrado o fato do governo de Ahmadinejad não ter avançado significativamente nas negociações sobre o programa nuclear, embora países como a Turquia e o Brasil estivessem dispostos a auxiliar, apresentando um acordo tripartite para o enriquecimento do urânio iraniano em usinas turcas, com o intuito de produzir energia pacífica. Por outro lado, Ahmadinejad mostrou um novo Irã ao mundo, no sentido do respeito à sua soberania, posição internacional e força tecnológica.

O segundo momento importante político iraniano é caracterizado pela eleição do atual presidente. Em 2013, Hassan Rohani, advogado e clérigo, com uma postura menos agressiva, vem atraindo a comunidade internacional para o diálogo, dando vozes à diplomacia e apaziguando as controvérsias. Desde que chegou ao poder, Rohani tem se caracterizado por ser muito mais pragmático e aberto ao diálogo que seu antecessor.

Em seu primeiro mandato, Rohani tem afirmado que o país tem o direito a desenvolver seu programa nuclear civil no seu próprio território. Porém, dadas as sanções por parte dos Estados Unidos e da União Europeia, a estratégia do 
novo presidente foi a de favorecer uma mudança de foco nas negociações de corte mais moderado e menos rígido, que até então, estava sendo conduzidas pelo chamado E3/EU+3. Assim, o objetivo de Rohani tem se concentrado em conseguir diminuir as sanções na medida do possível, reconhecendo igualmente a necessidade de fazer novas concessões à contraparte, ou seja, às potências nucleares ocidentais (Roca 2013, p.16).

Nesse sentido, destaca-se o papel que vem desempenhando o presidente Rohani com a nova orientação inserida às negociações do programa nuclear iraniano. Tanto para Roca (2013) quanto para Farhi e Lotfian (2013) ao analisar os impactos derivados da ascensão de Rohani ao poder, estabelecem que o novo presidente constitui um regional power balancer na sua versão defensiva. Isto é, uma nova performance do país através da consecução de quatro grandes objetivos: 1- a defesa da integridade territorial do país; 2- evitar o isolamento internacional; 3- fomentar a expansão dos investimentos e do comércio externo para promover o desenvolvimento interno; e finalmente, promover uma região menos militarizada e mais estável com seus vizinhos regionais.
Já com relação aos Estados Unidos a nova aproximação contemplaria uma relação de segurança diferente aos termos de um jogo de soma zero. Os balancers defensivos observam áreas de segurança de mútuo interesse para trabalhar conjuntamente tendo o equilíbrio político e estratégico como prioridade (Roca 2013, p. 12). Por isso, o novo relacionamento em construção entre os Estados Unidos, União Europeia e o Irã na era Rohani, estabelece um novo paradigma de diálogos diretos e através da negociação encontrar vias de solução entre os atores envolvidos.

A partir da análise anterior, percebe-se a necessidade de aprofundar um pouco mais no recente acordo iniciado em 2013 entre Estados Unidos, União Europeia e o Irã, o que coloca um novo desafio para todos os atores encontrarem mecanismos que permitam o entendimento definitivo sobre $\mathrm{o}$ programa nuclear iraniano no século XXI.

$O$ acordo negociado entre o Irã e o grupo E3/EU+3 (2013-2015)

O grupo E3/EU+3 foi criado em 2013 para negociar o impasse do programa nuclear iraniano. Nesta nomenclatura, prefere-se dividir os três países membros não europeus (Estados Unidos, Rússia e China) dos três 


\section{Muralf}

INTERNACIONAL

europeus (Inglaterra, França e Alemanha), embora existam outros documentos que utilizem a sigla $\mathrm{P} 5+1$ em alusão ao Conselho de Segurança mais a Alemanha. Não existe um modo oficial de escrita da sigla, mas neste artigo será utilizada a terminologia que é comum aos documentos que são redigidos pelas partes europeias, E3/EU+3, devido o local onde as negociações foram feitas, em território europeu, na cidade de Genebra.

Os trabalhos foram iniciados a partir da criação da comissão da Agência Internacional de Energia Atômica (AIEA) para o programa nuclear iraniano, a chamada Joint Commission of the $E 3 / E U+3$ and Iran, que foi orientada ao monitoramento, acompanhamento e cumprimento das normas e regras acordadas entre as partes. Esta comissão entende que o melhor caminho a seguir é o Irã comprovar a sua intenção de não produzir material bélico com seu programa nuclear, obedecendo os compromissos assumidos. Os procedimentos estabelecidos pela AIEA e as obrigações ratificadas pela República Islâmica do Irã e pelo grupo $\mathrm{E} 3 / \mathrm{EU}+3$ foram formalizadas $\mathrm{e}$ instrumentalizadas no Joint Plan of Action (JPOA), assinado em 24 de novembro de 2013, entrando em vigência a partir de 20 de janeiro de
Mural Internacional

V. $6 \mid$ N. 2

JUL-DEZ 2015
2014. Com a observância do acordo, a AIEA entende que é de direito do Irã o uso pacífico de seu programa nuclear sob a luz das regras do Tratado de NãoProliferação (TNP).

Os direitos e deveres são recíprocos, isto é, tanto o Irã deve cumprir os termos concertados, sendo transparente nos procedimentos necessários, quanto o grupo E3/EU+3 deve retirar todas as sanções aplicadas ao Irã que dizem respeito ao seu programa nuclear. Sendo assim, para que a confiança fosse construída progressivamente, a própria Agência propôs o cumprimento do acordo pelo sistema step-by-step (AIEA, 2013).

Trata-se de um esforço diplomático que tem trazido frutos que até então se esperavam que fossem impensáveis. A postura mais negociadora de Rohani pretende garantir uma maior transparência ao programa nuclear iraniano, assegurando o seu direito de uso de tecnologia nuclear com fins pacíficos, o que envolve não enriquecer Urânio-235 acima de 20\%, não reativar as usinas de Natanz, Fordow e Arak, como também permitir o livre acesso dos inspetores da AIEA sem aviso prévio. Os condicionantes para os membros do E3/EU+3 estão fundamentados nas suspensões dos embargos sobre importação de petróleo 
e fornecimentos tecnológicos. Com o cumprimento do JPOA, o Irã possivelmente terá um ganho na confiança e poderá receber o mesmo tratamento de qualquer outro Estado Parte não nuclear do TNP, o que significa dizer que a República Islâmica poderá ter o pleno direito de desenvolver e implementar energia nuclear com fins pacíficos (Hidalgo 2014, p.4).

O JPOA teve o prazo de validade de um semestre. Mas foi renovado por mútuo consentimento por mais um ano, e assim, o objetivo de que "all parties will work to maintain a constructive atmosphere for negotiations in good faith" (AIEA 2013, p. 1) foi alcançado. Após seis meses de vigência do acordo e respeitadas todas as regras, a AIEA propôs o estabelecimento de um novo acordo, só que dessa vez a longo prazo em consonância com as normas e procedimentos do TNP.

Nesse sentido, um novo acordo derivado do JPOA foi fechado em 14 de julho de 2015. O Joint Comprehensive Plan of Action (JCPOA) estabeleceu as regras a longo prazo para que a República Islâmica seja reconhecida como um Estado que cumpre a não-proliferação e faz uso pacífico de seu programa nuclear. É com o JCPOA que o grupo E3/EU+3 e o Estado iraniano demonstraram internacionais aos agentes compromissos para neutralizar a possível capacidade nuclear bélica iraniana e, com isto, certificaram que o diálogo e o esforço diplomático não foram em vão, confluindo em medidas concretas para a estabilidade da paz mundial.

As normas e procedimentos presentes no JCPOA são frutos de uma análise minuciosa e do aprimoramento daquilo que havia sido pactuado na elaboração do JPOA. Enquanto o acordo de curto prazo tinha um texto de quatro páginas, o de longo prazo, somando o conteúdo dos cinco anexos que o acompanham, contabiliza 112 páginas. É evidente o cuidado com que as negociações tiveram em dar conta de todos os pontos que poderiam resultar em outra coisa que não fosse a garantia de que $o$ programa nuclear iraniano é para fins pacíficos, e que se encontra baseado não somente na confiança, mas sim nos mecanismos de verificação internacionais.

Logo no preâmbulo do texto principal do JCPOA estão estabelecidas as regras gerais do acordo, as quais traduzem o comprometimento das partes com os termos pactuados, como igualmente sintetizam o espírito de cooperação e respeito que permearam a construção do 


\section{Muralf}

INTERNACIONAL
Mural Internacional

V. 6 | N. 2

JUL-DEZ 2015
JPOA e que agora estão presentes no JCPOA. Prova disto é o item viii do Acordo que diz:

The E3/EU+3 and Iran commit to implement this JCPOA in good faith and in a constructive atmosphere, based on mutual respect, and to refrain from any action inconsistent with the letter, spirit and intent of this JCPOA that would undermine its successful implementation. The $\mathrm{E} 3 / \mathrm{EU}+3$ will refrain from imposing discriminatory regulatory and procedural requirements in lieu of the sanctions and restrictive measures covered by this JCPOA. This JCPOA builds on the implementation of the Joint Plan of Action (JPOA) agreed in Geneva on 24 November 2013 (AIEA 2015, pp. 3-4).

Igualmente, o documento contempla os tópicos relativos às questões nucleares, cravando, por 15 anos, a taxa de 3,67\% como o nível máximo de enriquecimento de urânio em território iraniano. Há, ademais, a modernização de um reator de pesquisa de águapesada em Arak, com vistas a dar suporte à pesquisa nuclear pacífica e para a produção de radioisótopos para a indústria médica (AIEA 2015, pp. 7-8).

Para garantir a manutenção de uma atmosfera construtiva e positiva de confiança, foi elaborado o Plano de
Implementação, o qual determina cinco etapas que ratificam os propósitos pacíficos do programa nuclear iraniano. A implementação do JCPOA se dará na seguinte sequência: 1- Finalization Day, 2-Adoption Day, 3-Implementation Day, 4-Transition Day e 5-Termination Day. A lógica do step-by-step é mantida, o que significa dizer que só serão demandadas as tratativas de uma etapa quando as regras da anterior forem cumpridas, permitindo a consolidação de um sistema onde a confiança é construída progressiva e mutuamente.

\section{Considerações finais}

É possível entender, em linhas gerais, a gênese do programa nuclear iraniano que remonta ao período dos anos 1950 e ao apoio dos Estados Unidos, os quais endossavam que o desenvolvimento de um projeto como este significaria “Átomos para a Paz” no Oriente Médio. Dada a inflexão de parceria para a posição anti-imperialista iraniana com o Ocidente, sobretudo em relação ao governo estadunidense, após a Revolução de 1979, o programa nuclear iraniano foi paralisado e o país passou a sentir as duras sanções aplicadas pelo Ocidente que via seus interesses contrariados e até mesmo ameaçados com a islamização do Estado iraniano.

No prosseguimento dos fatos, pode-se diferenciar claramente três fases do 
programa nuclear iraniano a partir da segunda metade dos anos 1990. A primeira consiste em um período de retomada do debate e do desenvolvimento de tecnologia nuclear os quais marcaram a retórica da administração de Kathami. Mas é somente com o governo de Ahmadinejad que, de fato, o programa nuclear é acelerado, inaugurando assim, a etapa de dissuasão. É na continuidade deste processo que é iniciada a fase de negociação com a eleição de Rohani. Mais moderado do que o seu antecessor, herda de Ahmadinejad todo o discurso dissuasório e tem seu governo caracterizado até os dias de hoje pela celebração e cumprimento dos termos acordados no JPA junto às potências ocidentais, somando forças ao espírito de cooperação e diálogo internacionais.

O JCPOA assinado em 2015 ainda deve enfrentar as respectivas ratificações dos poderes legislativos dos países que participaram nas negociações. Possivelmente, a maior dificuldade será o debate no Congresso dos Estados Unidos, porém, caso seja rejeitado, existe o mecanismo de veto por parte do executivo e o presidente poderá dar inicio à implementação dos compromissos estabelecidos no acordo por via unilateral.
O JCPOA permite que o Irã limite o seu programa nuclear e o coloque sob a verificação internacional conforme os procedimentos estabelecidos através dos regimes e organismos voltados para essa área. O maior ganho para o Irã, sem dúvida, é a possibilidade de desenvolver pesquisa com urânio, cuja atividade que passa a ser reconhecida pela comunidade internacional com caráter pacífico. Por sua vez, as potências se comprometem em liberar os ativos iranianos que estavam congelados devido às penalidades impostas, as quais serão reduzidas de forma progressiva a partir de 2016, incluindo as restrições relativas ao setor de aviação, de indústria em geral e de comércio de materiais tecnológicos necessários para a produção de energia nuclear.

Em resumo, o acordo JCPOA permite a normalização da presença do Irã no cenário internacional (pela redução progressiva dos embargos) e a percepção de confiança no seu plano nuclear por parte do Ocidente (pela submissão às verificações e mecanismos de controle internacional). Assim, podese argumentar que com a implementação efetiva do JCPOA a partir de 2016, é dado inicio a uma nova era ou fase do programa nuclear iraniano, caracterizada agora pela cooperação e a diplomacia nuclear entre o Irã e Ocidente. 


\section{Muralf}

INTERNACIONAL

Mural Internacional

V. $6 \mid$ N. 2

JUL-DEZ 2015

\section{Referências}

Agência Internacional de Energia Atômica. (2013). 'Joint Plan of Action'. Genebra. Disponível em: <http://eeas.europa.eu/statements/docs/2013/131124_03_en.pdf>. [Acesso em: 10 Nov. 2015].

Agência Internacional de Energia Atômica. (2015). 'Joint Comprehensive Plan of Action'. Genebra. Disponível em: <http://eeas.europa.eu/statementseeas/docs/iran_agreement/iran_joint-comprehensive-plan-of-action_en.pdf $\rangle$. [Acesso em: 10 Nov. 2015].

Bruno, G. (2010). 'Iran's Nuclear Program'. Council on Foreign Relations. Disponível em: http://www.cfr.org/iran/irans-nuclear-program/p16811. [Acessado em: 20 Ago. de 2014].

Cirincione, J.; Wolfsthal, J.; Rajkumar, M. (2005). Deadly Arsenals:Nuclear, Biological, and Chemical Threats. 2. ed. Washington: Carnegie Endowment.

Farhi, F.; Lotflan, S. (2013). 'Iranian Foreign Policy After The Election: Realist and Islamic Idealists Face Off'. Foreign Affairs. Disponível em: http://www.foreignaffairs.com/articles/139495/farideh-farhi-and-saidehlotfian/iranian-foreign-policy-after-the-election. [Acessado em: 10 Dez. de 2014].

Garcia, J. (2012). 'Programa Nuclear Iraní: una Visión Técnica'. Documento Opinión, No. 73, septiembre. Instituto Español de Estudios Estratégicos - IEEE. Disponível em: http://www.iee.es/Galerias/fichero/docs_opinion/2012/DIEEEO732012_ProgramaNuclearIrani_Ortega.pdf. [Acessado em: 30 Nov. de 2014].

Hidalgo, M. (2014). 'El Acuerdo Nuclear del P3+3 e Irán y su Repercusión en Oriente Medio'. Documento Análisis. No. 06, Janeiro. Instituto Español de Estudios Estratégicos - IEEE. Disponível em: http://www.ieee.es/Galerias/fichero/docs_analisis/2014/DIEEEA062014_ProgramaNuclearIrani_MMHG.pdf. [Acessado em: 14 Jan. de 2015].

Hobsbawn, E. (1995). Era dos Extremos: o Breve Século XX 1914-1991. São Paulo: Companhia das Letras. 
Ibañez, F. (2011). 'El Programa Nuclear Iraní: Estado de la Cuestión y Posibles Escenários'. Relaciones Internacionales, No. 16. Febrero. GERI-UAM. Disponível em: $\quad$ http://www.relacionesinternacionales.info/ojs/article/download/271/236.pdf. [Acessado em: 02 Dez. de 2014].

Roca, X. (2013). 'El Impacto del Nuevo Presidente Hassan Rohani em la Política Exterior y de Seguridad Iraní'. Documento Opinión, No. 61, 2 de julio. Instituto Español de Estudios Estratégicos - IEEE. Disponível em: http://www.ieee.es/Galerias/fichero/docs_opinion/2013/DIEEEO612013_Elecciones_Iran_XavierSertvija.pdf. [Acessado em: 08 Dez. 2014].

Vizentini, P. (2010). 'República Islâmica do Irã: Potência Emergente ou Regime em Crise?'. Nerint, Porto Alegre, Agosto de 2010. pp. 1-7 [online]. Disponível em: http://www.ufrgs.br/nerint/folder/artigos/artigo1083.pdf. [Acessado em: 11 Nov. de 2014].

Zaccara, L. (2006). 'Irán y la Cuestión Nuclear'. Revista Política Exterior, No. 109, enero/febrero. http://www.uam.es/otroscentros/TEIM/archivos/documentos/lucianozaccara_polext.p df. [Acessado em: 01 Dez. de 2014]. 